\title{
Mobilidade do Sulfentrazone em LATOSSOlO VeRMelHo E EM Chernossolo ${ }^{1}$
}

\author{
Mobility of Sulfentrazone in Red Latosol and Chernosol \\ ROSSI, C.V.S. ${ }^{2}$, ALVES, P.L.C.A. ${ }^{3}$ e MARQUES JÚNIOR, J. ${ }^{4}$
}

\begin{abstract}
RESUMO - Este trabalho objetivou determinar a mobilidade do sulfentrazone em duas classes de solos em função de índices pluviométricos, bem como possíveis influências das propriedades químicas e físicas de Latossolo Vermelho e Chernossolo com diferentes teores de ferro na ação do herbicida. Foram utilizados como recipientes 36 tubos de PVC de $10 \mathrm{~cm}$ de diâmetro por $50 \mathrm{~cm}$ de comprimento. Os recipientes foram preenchidos com os solos e umedecidos a $65 \%(\mathrm{p} / \mathrm{p})$ da capacidade de saturação, quando se fez a aplicação do sulfentrazone (800 $\mathrm{g} \mathrm{ha}^{-1}$ de i.a.) na área exposta dos solos. Na seqüência, foram simuladas chuvas diárias de $10 \mathrm{~mm}$ até atingir o índice pluviométrico desejado (30,60 e $90 \mathrm{~mm}$ ), sendo, posteriormente, desmontados seis tubos de cada solo (com e sem aplicação). Foram semeadas cinco sementes de sorgo (Sorghum bicolor) nas profundidades de 2,5; 7,5; 12,5; 17,5; 22,5; e 30,0 cm, mantidas em casa de vegetação por 15 dias para avaliação da germinação e do crescimento inicial. Decorrido esse tempo, foi realizada avaliação de possíveis alterações morfofisiológicas que pudessem ser caracterizadas como efeitos tóxicos do produto e mediuse o comprimento da parte aérea até a última lígula visível. As partes aéreas foram secas em estufa com circulação forçada de ar $\left(70{ }^{\circ} \mathrm{C}\right.$ por 96 horas), para obtenção de matéria seca. No Chernossolo ocorreu uniformidade da distribuição do produto ao longo do tubo, proporcional à precipitação, e no Latossolo Vermelho o sulfentrazone foi pouco móvel, permanecendo na camada superficial, independentemente da precipitação.
\end{abstract}

Palavras-chave: solos, herbicida, chuva, lixiviação, profundidade.

\begin{abstract}
This study aimed to determine the mobility of sulfentrazone in two soil classes as a function of increasing rain indices, as well as possible influences of chemical and physical properties of soils with different iron oxide contents (Red Latosol and Chernosol), on herbicide action. The containers consisted of $36 \mathrm{PVC}$ tubes $(10 \mathrm{~cm}$ diameter $x 50 \mathrm{~cm}$ long), which were filled with the soils and saturated in 65\% ( $w / w)$ water followed by sulfentrazone ( $800 \mathrm{~g} \mathrm{ha}^{-1}$ of a.i.) application on the exposed area. Daily rainfalls of $10 \mathrm{~mm}$ were subsequently simulated and, as the desired rain indices were reached $(30,60$ and $90 \mathrm{~mm}$ ), six PVC tubes from each soil (with and without application) were disassembled. Five sorghum (Sorghum bicolor) seeds were seeded on soil at depths of 2.5; 7.5; 12.5; 17.5; 22.5 and $30.0 \mathrm{~cm}$, and maintained under greenhouse conditions for 15 days for germination and initial growth evaluation. Also, evaluation of possible morphophysiological changes that could be characterized as toxic effects of the product was carried out and shoot length up to the last visible ligule was measured. The shoots were bagged and dried in a forced draught over $\left(70^{\circ} \mathrm{C}\right.$ for $\left.96 \mathrm{~h}\right)$ to dry matter determination. There was a uniform distribution of the product on the length of the tube, proportional to the rainfall on Chernosol; on Red Latosol, sulfentrazone had little mobility, remaining on the top $2.5 \mathrm{~cm}$, regardless of the rainfall.
\end{abstract}

Key words: soils, herbicide, rain, leaching, depth.

1 Recebido para publicação em 22/3/2005 e na forma revisada em 25/11/2005.

Parte do trabalho de graduação apresentado à FCAV/UNESP - Jaboticabal, para graduação em Agronomia do primeiro autor.

2 Pós-Graduando (Doutorado) em Agricultura. FCA/UNESP - Botucatu. Fazenda Experimental Lageado, s/n. Departamento de Produção Vegetal - Agricultura/Matologia, Caixa Postal 237, 18603-970 Botucatu-SP, Tel.: (14) 38117100 ou (14) 91410988 , <cavsragro@msn.com>; ${ }^{3}$ Professor D.S., Departamento de Biologia Aplicada à Agropecuária, FCAV/UNESP-Jaboticabal, Via de Acesso Prof. Paulo Donato Castellane, s/n., 14884-900 Jaboticabal-SP; ${ }^{4}$ Professor D.S., Departamento de Solos e Adubos, FCAV/UNESP-Jaboticabal. 


\section{INTRODUÇÃO}

No solo, quando o herbicida é aplicado em pré-emergência, este pode sofrer sorção, lixiviação e/ou degradação por processos físicos, químicos e biológicos, além de ser absorvido pelas plantas daninhas e/ou cultivadas. No entanto, esses processos são dependentes do tipo de solo e das condições climáticas e conhecê-los é importante para prever o comportamento de herbicidas nas classes de solo e para seleção de dosagens adequadas, bem como para evitar efeitos prejudiciais ao ambiente e às culturas subseqüentes (Brady, 1974; Velini, 1992; Resende et al., 1995).

O movimento descendente dos herbicidas no solo é mais influenciado pelo conteúdo e pelo tipo de matéria orgânica, composição e distribuição do tamanho das partículas do solo, $\mathrm{pH}$, densidade do solo, tamanho e distribuição dos poros. No caso dos herbicidas de elevada capacidade adsortiva, o conteúdo de matéria orgânica é geralmente um fator importante, pois, quanto mais alto, maior a adsorção e, com isso, menor a lixiviação (Sprankle et al., 1975; Mandhun et al., 1986; Senesi et al., 1994; Rodrigues et al., 2000). Em solos arenosos, a lixiviação será ainda maior do que em siltosos ou argilosos (Nicholls, 1988).

O processo de adsorção de herbicidas ácidos pelos solos não tem contribuição significativa dos teores de argila, porém é favorecido pelos óxidos e hidróxidos de ferro e alumínio e pela caulinita, uma vez que a carga superficial desses minerais de argila é dependente do $\mathrm{pH}$, e a adsorção é resultado da troca iônica entre minerais e o herbicida em sua fase aniônica em valores baixos de $\mathrm{pH}$ (Green, 1974; Loux et al., 1989).

Dois aspectos apresentados pela lixiviação são importantes: primeiramente, por ser fundamental para a incorporação superficial da maioria dos herbicidas, atingindo sementes ou plantas em germinação; e, quando excessiva, a lixiviação pode carreá-los a camadas mais profundas do solo, limitandolhes a ação e podendo, inclusive, promover contaminação do lençol freático (Velini, 1992).

Os Latossolos constituem o mais expressivo agrupamento de solos da quadrícula de
Ribeirão Preto-SP, representando 77\% (Oliveira $\&$ Prado, 1987). No caso do Chernossolo, tratase de um solo com predominância de argila 2: 1 , que tem seqüência de horizontes $\mathrm{A}-\mathrm{Bi}-\mathrm{C}$ ou A-Bt-C, em cuja diferenciação avulta o espesso pretejamento dos horizontes superficiais, podendo alcançar o horizonte B (Oliveira, 1992). O Latossolo Vermelho-Escuro é classificado como Latossolo Vermelho (LV), e o Brunizém como Chernossolo (M) (Embrapa, 1999).

A quantidade dos óxidos de ferro presentes na fração argila dos solos tropicais, como nos Latossolos, é tão importante para conhecer as propriedades destes solos que o sistema de classificação de solos empregado pela Embrapa (1979) utiliza como critério para as distinções desta classe o teor de óxido de ferro total (Kämpf \& Schwertman, 1983; Fontes \& Need, 1991).

O sulfentrazone, 2', 4'-dichloro-5-(4difluoromethyl-4,5-dihydro-3-methyl-5-oxo1H-1,2,4-triazol-1-yl) methanesulfonanilide, do grupo químico das triazolinonas, é um herbicida para aplicação preferencialmente em pré-emergência, controlando várias espécies de plantas daninhas, mono e dicotiledôneas, das culturas da cana-de-açúcar, soja, café e eucalipto, além do seu uso em pátios industriais. Ele apresenta solubilidade em água de $490 \mathrm{mg} \mathrm{L}^{-1}$ e pressão de vapor de $1 \times 10^{-9} \mathrm{~mm} \mathrm{Hg}$ a $25{ }^{\circ} \mathrm{C}$. No solo, a mobilidade é moderada, de baixa adsorção, com Koc a 43, pKa a 6,56 e Kow a 1,48 , sendo a decomposição microbiana a via mais importante de degradação do produto no solo; sua meia-vida em solos brasileiros é, em média, de 180 dias (Rodrigues \& Almeida, 2005).

Nesse contexto, o conhecimento da relação sulfentrazone-solo é muito importante. Portanto, o experimento teve o objetivo de avaliar o movimento vertical do sulfentrazone no perfil de um Latossolo Vermelho e de um Chernossolo em função de índices pluviométricos, bem como possíveis influências das propriedades químicas e físicas de solos com diferentes teores de ferro sobre o sulfentrazone.

\section{MATERIAL E MÉTODOS}

O experimento foi instalado e conduzido em casa de vegetação na FCAV/UNESP Jaboticabal-SP. O substrato utilizado foi coletado na camada arável $(0-20 \mathrm{~cm})$ de um 
Latossolo Vermelho eutrófico (LV) textura argilosa, situado em Jaboticabal-SP $\left(48^{\circ} 18^{\prime} \mathrm{W}\right.$ e $21^{\circ} 15^{\prime} \mathrm{S}$ ), e de um Chernossolo (M) textura arenosa, situado no município de Monte Alto$\mathrm{SP}\left(48^{\circ} 31^{\prime} \mathrm{W}\right.$ e $\left.21^{\circ} 16^{\prime} \mathrm{S}\right)$. Os solos foram coletados em áreas cujo histórico não apresentava qualquer aplicação de herbicida.

Após a coleta, os solos foram secos à sombra por 48 horas, depois passados em peneiras com malha de $5 \mathrm{~mm}$; amostras foram retiradas para a análise química (Tabela 1) e granulométrica, para classificação da textura (Tabela 2).

A análise granulométrica da terra fina foi realizada pelo método da pipeta (Embrapa, 1979). O pH foi determinado potenciometricamente, com relação $1: 2,5$ de solo: $\mathrm{CaCl}_{2}$ $0,01 \mathrm{~mol} \mathrm{~L}^{-1}$. O Ca, Mg e K trocáveis e o P disponível foram extraídos pelo método da resina trocadora de íons (Raij \& Quaggio, 1983), e a matéria orgânica, pelo método da Embrapa (1979).

A determinação da densidade e da capacidade de saturação dos solos foi feita pelo método gravimétrico (Embrapa, 1979), para o preenchimento uniforme dos tubos de PVC (recipientes) com os materiais de solos, simulando a densidade natural deles.

Como recipientes foram utilizados 36 tubos de PVC de $10 \mathrm{~cm}$ de diâmetro por $50 \mathrm{~cm}$ de comprimento. Esses tubos foram seccionados ao meio longitudinalmente e fixados com fita adesiva, reconstituindo o original. As bases dos tubos foram fechadas por meio de uma tela tipo mosquiteiro.

Após a montagem dos conjuntos com os tubos de PVC preenchidos com os solos, estes foram umedecidos até $65 \%$ de sua capacidade de saturação (Embrapa, 1979) e realizou-se a aplicação do sulfentrazone (800 $\mathrm{g} \mathrm{ha}^{-1}$ de i.a.) na superfície exposta dos solos contidos nos tubos de PVC. As condições climáticas durante a aplicação foram: temperatura do ar de $22,5^{\circ} \mathrm{C}$ e do solo de $28,8^{\circ} \mathrm{C}(\mathrm{LV})$ e $28,1^{\circ} \mathrm{C}(\mathrm{M})$, umidade relativa de 56\%, com ausência de vento e $12,5 \%$ de nuvens no céu. As aplicações do produto foram feitas com pulverizador costal mantido a pressão constante (ar comprimido), munido de barra com quatro bicos XR 110.02, regulado para uma vazão de $200 \mathrm{~L} \mathrm{ha}^{-1}$.

Foram simuladas chuvas diárias de $10 \mathrm{~mm}$ $\mathrm{e}$, à medida que se atingia o índice pluviométrico desejado $(30,60$ ou $90 \mathrm{~mm})$, eram desmontados seis tubos de cada solo, separando-se as duas metades e deitando-as onde foram postas para germinar cinco sementes de sorgo (Sorghum bicolor) a 2,5; 7,5; 12,5; 17,5; 22,5; e $30,0 \mathrm{~cm}$ da superfície na qual se aplicou o produto ou não. $\mathrm{O}$ ensaio de germinação e crescimento inicial foi conduzido por 15 dias.

O delineamento experimental utilizado para cada classe de solo (LV e M) foi em blocos casualizados, com seis tratamentos constituindo as parcelas e a interação entre os fatores principais (três índices pluviométricos com ou sem herbicida) e as seis profundidades de semeadura as subparcelas, em três repetições para cada classe de solo. Cada parcela experimental constou de um tubo de $50 \mathrm{~cm}$, composto por duas metades.

Tabela 2 - Resultados da análise* granulométrica de uma amostra dos solos utilizados como substratos

\begin{tabular}{|c|c|c|c|c|c|}
\hline $\begin{array}{c}\text { Classe de } \\
\text { Solo }\end{array}$ & \multicolumn{5}{|c|}{ Granulometria (\%) } \\
\cline { 2 - 6 } & Argila & Limo & Areia fina & Areia grossa & Textura \\
\hline LV & 55 & 21 & 16 & 8 & Argilosa \\
\hdashline M & 14 & 8 & 34 & 44 & Arenosa \\
\hline
\end{tabular}

* Realizada pelo Departamento de Solos e Adubos - FCAV/UNESP Jaboticabal-SP.

Tabela 1 - Análise* química de rotina e de óxido de ferro dos solos Latossolo Vermelho (LV) e Chernossolo (M) utilizados na avaliação da mobilidade do sulfentrazone

\begin{tabular}{|c|c|c|c|c|c|c|c|c|c|c|c|}
\hline \multirow{2}{*}{ Solo } & \multirow{2}{*}{$\begin{array}{c}\mathrm{pH} \\
\left(\mathrm{CaCl}_{2}\right)\end{array}$} & \multirow{2}{*}{$\begin{array}{l}\text { M.O. } \\
\left(\mathrm{g} \mathrm{dm}^{-3}\right)\end{array}$} & \multirow{2}{*}{$\begin{array}{c}\text { P res. } \\
\left(\mathrm{mg} \mathrm{dm}^{-3}\right)\end{array}$} & \multicolumn{6}{|c|}{$\left(\mathrm{mmol}_{\mathrm{c}} / \mathrm{dm}^{3}\right)$} & \multirow{2}{*}{$\begin{array}{c}\mathrm{V} \\
(\%)\end{array}$} & \multirow{2}{*}{$\begin{array}{c}\mathrm{Fe}_{2} \mathrm{O}_{3} \\
(\%)\end{array}$} \\
\hline & & & & $\mathrm{K}$ & $\mathrm{Ca}$ & $\mathrm{Mg}$ & $\mathrm{H}+\mathrm{AL}$ & SB & $\mathrm{T}$ & & \\
\hline LV & 5,9 & 15 & 8 & 4,0 & 23 & 6 & 20 & 33,0 & 53,0 & 62 & 15,12 \\
\hline M & 5,1 & 29 & 31 & 0,9 & 100 & 20 & 31 & 120,9 & 151,9 & 80 & 3,28 \\
\hline
\end{tabular}

* Realizada pelo Departamento de Solos e Adubos - FCAV/UNESP - Jaboticabal. 
Aos 15 dias após a semeadura, foi realizada uma avaliação visual de possíveis alterações morfofisiológicas nas plântulas de sorgo que pudessem ser caracterizadas como efeitos tóxicos do produto. Essa avaliação foi baseada em critérios qualitativos, segundo a escala de notas da EWRC (1964), sendo feita para cada linha de semeadura, que representou uma profundidade. Na seqüência, realizou-se a medição do comprimento da parte aérea das plântulas, as quais foram posteriormente cortadas e postas para secar em estufa com circulação forçada de $\operatorname{ar}\left(70{ }^{\circ} \mathrm{C}\right.$ por 96 horas), para obtenção da biomassa seca. A partir do número de plântulas medidas, pôde-se atribuir a porcentagem de emergência para cada linha de semeadura.

Os dados obtidos foram submetidos à análise de variância pelo teste $\mathrm{F}$, sendo as médias comparadas pelo teste de Tukey a 5\% de probabilidade. Os dados de porcentagem de emergência obtidos foram transformados em $\operatorname{arcsen} \sqrt{(x+1) / 100}$.

\section{RESULTADOS E DISCUSSÃO}

Com base na escala da EWRC (1964), foram atribuídas notas de toxicidade nas plântulas para cada linha de semeadura. Nas testemunhas referentes às classes de solo, a intoxicação nas plântulas de sorgo foi nula, ou seja, a nota foi 1 para todas.

\section{Latossolo Vermelho (LV)}

Com a chuva simulada de $30 \mathrm{~mm}$, o sulfentrazone provocou injúrias severas nas plântulas de sorgo provenientes de sementes que foram colocadas para germinar a $2,5 \mathrm{~cm}$ superficiais, as quais apresentaram sintomas fortes de intoxicação (nota 7 - Tabela 3), com amarelecimento, necrose e encarquilhamento das folhas. Dos 7,5 aos 30,0 cm de profundidade, a intoxicação das plântulas foi nula (nota 1).

Com as precipitações simuladas de 60 e $90 \mathrm{~mm}$, as plântulas que se encontravam a $2,5 \mathrm{~cm}$ superficiais apresentaram sintomas muito fortes de intoxicação (nota 8) pelo sulfentrazone, estando quase mortas. Nas plântulas que se encontravam aos $7,5 \mathrm{~cm}$ os sintomas foram leves (nota 3), com amarelecimento das folhas e menor altura, enquanto dos 12,5 aos $30,0 \mathrm{~cm}$ de profundidade a intoxicação foi nula (nota 1).

Com base nesses resultados visuais de fitotoxicidade do sulfentrazone nas plântulas de sorgo, observou-se tendência de acúmulo do herbicida nos $2,5 \mathrm{~cm}$ superficiais do solo, com baixa lixiviação até os $7,5 \mathrm{~cm}$, mesmo com os índices crescentes de precipitação.

Tabela 3 - Notas de toxicidade das plântulas de sorgo em Latossolo Vermelho (LV) e Chernossolo (M) tratados com sulfentrazone e submetidos a índices pluviométricos crescentes (segundo a escala de notas da EWRC, 1964)

\begin{tabular}{|c|c|c|c|c|c|c|}
\hline \multirow{2}{*}{$\begin{array}{c}\text { Profundidade } \\
(\mathrm{cm})\end{array}$} & \multicolumn{5}{|c|}{ Classe de solo/precipitação (mm) } \\
\cline { 2 - 7 } & \multicolumn{3}{|c|}{ LV } & \multicolumn{3}{|c|}{ M } \\
\cline { 2 - 7 } & 30 & 60 & 90 & 30 & 60 & 90 \\
\hline 2,5 & 7 & 8 & 8 & 8 & 8 & 8 \\
\hline 7,5 & 1 & 3 & 3 & 1 & 2 & 2 \\
\hline 12,5 & 1 & 1 & 1 & 1 & 1 & 1 \\
\hline 17,5 & 1 & 1 & 1 & 1 & 1 & 1 \\
\hline 22,5 & 1 & 1 & 1 & 1 & 1 & 1 \\
\hline 30,0 & 1 & 1 & 1 & 1 & 1 & 1 \\
\hline
\end{tabular}

Obs.: nas testemunhas referentes às classes de solo, a intoxicação nas plântulas de sorgo foi nula, ou seja, a nota foi 1 para todas. Média de três repetições.

A aplicação do sulfentrazone no Latossolo Vermelho não afetou a emergência das plântulas de sorgo no período avaliado, independentemente da profundidade de semeadura (Tabela 4). Por outro lado, as plântulas do solo não tratado com sulfentrazone e submetido a $30 \mathrm{~mm}$ de chuva apresentaram-se maiores que as do mesmo tratamento exposto a $90 \mathrm{~mm}$ e, ainda, com biomassa seca maior do que das tratadas com sulfentrazone e das testemunhas expostas a 60 ou $90 \mathrm{~mm}$. Considerando-se que o trabalho foi realizado com colunas preenchidas com o mesmo solo, esse resultado pode ter sido decorrente do aumento da lixiviação de nutrientes pela chuva simulada, refletindo em redução nas características de tamanho e biomassa seca das plântulas de sorgo.

Quanto ao efeito da profundidade, independentemente da aplicação ou não do sulfentrazone e do índice pluviométrico simulado, não se constatou diferença significativa na emergência e na biomassa seca das plântulas oriundas da semeadura nas diferentes profundidades. Contudo, observou-se 
efeito significativo da interação entre os fatores principais (três índices pluviométricos com ou sem herbicida) sobre a altura e a emergência das plântulas de sorgo (Tabela 4). Aos $2,5 \mathrm{~cm}$ superficiais, a altura da plântula de sorgo foi menor que a das demais, podendo-se atribuir a esse fato uma maior disponibilidade do sulfentrazone na superfície do LV.

Na Tabela 5, pode-se observar que no solo tratado com sulfentrazone as plântulas de sorgo oriundas da semeadura aos $2,5 \mathrm{~cm}$ de profundidade mostraram-se menores que as das demais nos três índices pluviométricos estudados; com a precipitação de $90 \mathrm{~mm}$ esse efeito se estendeu até os $7,5 \mathrm{~cm}$. Ao analisar o efeito dos tratamentos dentro de cada profundidade, observou-se que ele foi significativo aos $2,5 \mathrm{~cm}$, onde a aplicação de sulfentrazone sob as três precipitações resultou em plântulas menores, e aos $7,5 \mathrm{~cm}$, onde apenas a de $90 \mathrm{~mm}$ resultou em plântulas menores. Nas demais profundidades de semeadura não se constataram significativos efeitos do sulfentrazone sobre a altura das plântulas de sorgo.

Tabela 4 - Efeito da aplicação do sulfentrazone no Latossolo Vermelho (LV), sob diferentes precipitações, sobre a altura, emergência e biomassa das plântulas de sorgo nas diferentes profundidades (média de três repetições)

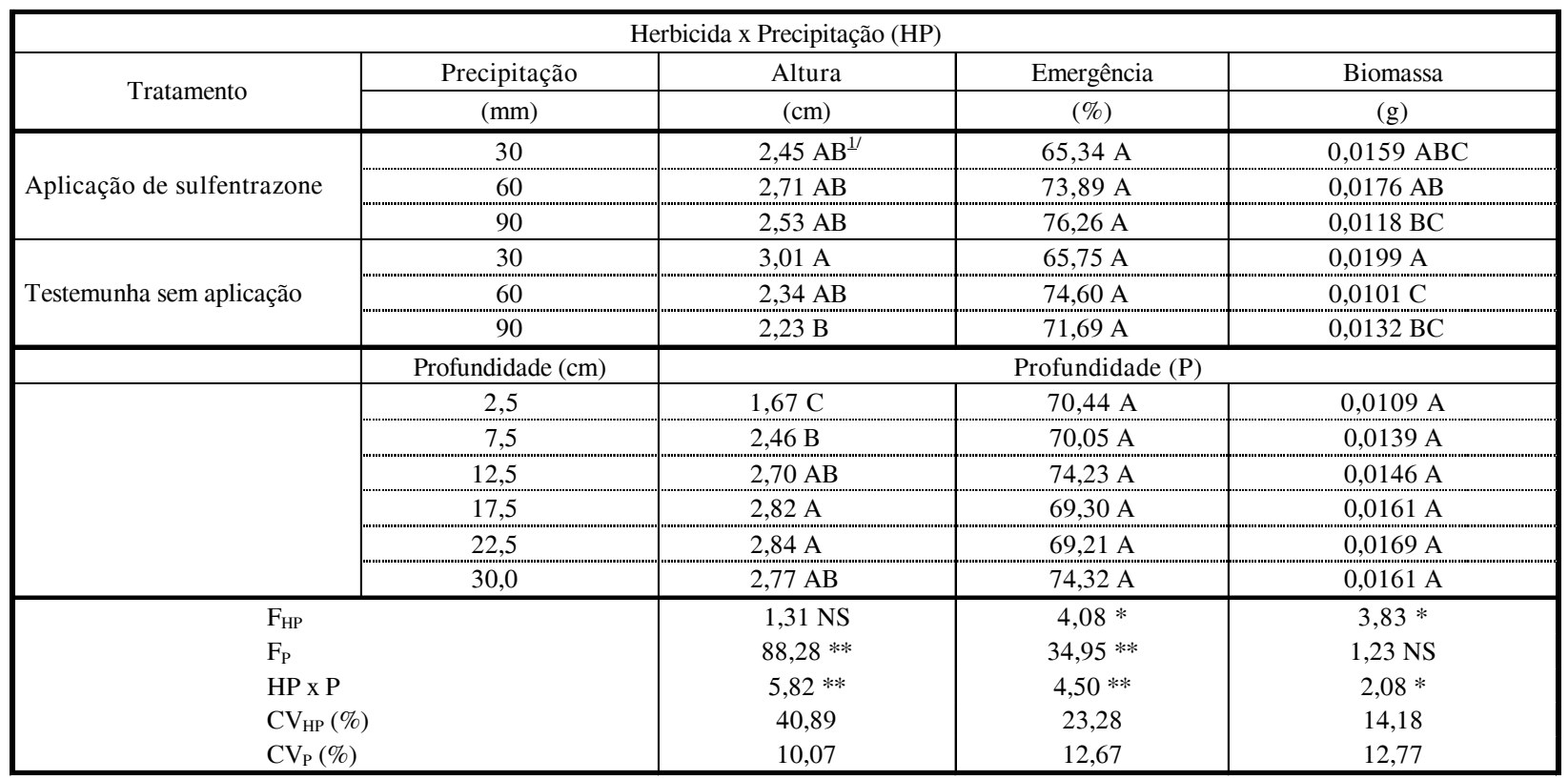

1/ Médias seguidas de mesma letra não diferem significativamente pelo teste de Tukey a $5 \%$. ** e *: Significativo a 1 e $5 \%$ pelo teste $\mathrm{F}$, respectivamente; NS: não-significativo pelo teste $\mathrm{F}$.

Tabela 5 - Altura das plântulas de sorgo (cm), no Latossolo Vermelho (LV), obtida no desdobramento da interação entre as diferentes profundidades e os tratamentos com e sem aplicação do sulfentrazone sob as diferentes precipitações (média de três repetições)

\begin{tabular}{|c|c|c|c|c|c|c|}
\hline \multirow{2}{*}{$\begin{array}{c}\text { Profundidade } \\
(\mathrm{cm})\end{array}$} & \multicolumn{3}{|c|}{ Sulfentrazone } & \multicolumn{3}{c|}{ Testemunha } \\
\cline { 2 - 6 } & $30 \mathrm{~mm}$ & $60 \mathrm{~mm}$ & $90 \mathrm{~mm}$ & $30 \mathrm{~mm}$ & $60 \mathrm{~mm}$ & $90 \mathrm{~mm}$ \\
\hline 2,5 & $1,16 \mathrm{Bbc}^{1 /}$ & $1,12 \mathrm{Bc}$ & $1,02 \mathrm{Cc}$ & $2,75 \mathrm{Aa}$ & $1,93 \mathrm{Ab}$ & $2,05 \mathrm{Ab}$ \\
\hline 7,5 & $2,74 \mathrm{Aab}$ & $2,74 \mathrm{Aab}$ & $1,86 \mathrm{Bb}$ & $2,80 \mathrm{Aa}$ & $2,43 \mathrm{Aab}$ & $2,19 \mathrm{Aab}$ \\
\hline 12,5 & $2,68 \mathrm{Aa}$ & $2,90 \mathrm{Aa}$ & $3,09 \mathrm{Aa}$ & $2,85 \mathrm{Aa}$ & $2,36 \mathrm{Aa}$ & $2,35 \mathrm{Aa}$ \\
\hline 17,5 & $2,78 \mathrm{Aab}$ & $3,21 \mathrm{Aab}$ & $3,30 \mathrm{Aa}$ & $2,92 \mathrm{Aab}$ & $2,45 \mathrm{Aab}$ & $2,29 \mathrm{Ab}$ \\
\hline 22,5 & $2,78 \mathrm{Aab}$ & $3,14 \mathrm{Aab}$ & $3,12 \mathrm{Aab}$ & $3,35 \mathrm{Aa}$ & $2,38 \mathrm{Ab}$ & $2,25 \mathrm{Ab}$ \\
\hline 30,0 & $2,60 \mathrm{Aab}$ & $3,12 \mathrm{Aab}$ & $2,79 \mathrm{Aab}$ & $3,41 \mathrm{Aa}$ & $2,48 \mathrm{Ab}$ & $2,24 \mathrm{Ab}$ \\
\hline
\end{tabular}

${ }^{1 /}$ Médias seguidas de mesma letra não diferem significativamente pelo teste de Tukey a 5\%. Letras maiúsculas, na coluna, comparam os efeitos das diferentes profundidades. Letras minúsculas, na linha, comparam os efeitos das precipitações sem aplicação e com aplicação do sulfentrazone. 
Pode-se observar na Tabela 6 que o sulfentrazone, quando submetido aos três índices pluviométricos estudados, não afetou a emergência das plântulas de sorgo em relação às testemunhas. Foi verificado efeito da profundidade somente no tratamento em que se empregou sulfentrazone sob $60 \mathrm{~mm}$ de precipitação, mas sem que os dados se mostrassem conclusivos.

\section{Chernossolo (M)}

Para a chuva simulada de $30 \mathrm{~mm}$, observou-se que as plântulas de sorgo provenientes da germinação aos $2,5 \mathrm{~cm}$ superficiais apresentaram sintomas muito fortes de intoxicação pelo sulfentrazone (nota 8 - Tabela 3), com amarelecimento, necrose e encarquilhamento das folhas. Dos 7,5 aos 30,0 cm de profundidade, a intoxicação foi nula (nota 1).

Com as precipitações simuladas de 60 e $90 \mathrm{~mm}$, o sulfentrazone proporcionou injúrias muito severas, com as plântulas apresentando sintomas muito fortes (nota 8) nos $2,5 \mathrm{~cm}$ superficiais. Nos $7,5 \mathrm{~cm}$, os sintomas foram muito leves (nota 2), com leve amarelecimento das folhas e pouca redução na altura das plântulas. Dos 12,5 aos 30,0 cm de profundidade, a intoxicação foi nula (nota 1).

Com base nesses resultados visuais de toxicidade do sulfentrazone das plântulas de sorgo, observou-se tendência de acúmulo do herbicida nos $2,5 \mathrm{~cm}$ superficiais do solo, com baixa lixiviação até os $7,5 \mathrm{~cm}$, mesmo com o aumento de precipitação.

A aplicação do sulfentrazone no Chernossolo sob os três índices pluviométricos não resultou em alterações na emergência, altura e biomassa seca das plântulas de sorgo, independentemente da profundidade de semeadura (Tabela 7). A profundidade, sem levar em conta o efeito da aplicação ou não do sulfentrazone e dos índices pluviométricos, afetou apenas a altura e a biomassa seca das plântulas; com o aumento da profundidade, observou-se aumento gradual dessas características.

Para esta classe de solo foi observado efeito da interação entre os fatores principais (três índices pluviométricos com ou sem herbicida) sobre a altura e a biomassa seca das plântulas de sorgo.

Planta Daninha, Viçosa-MG, v. 23, n. 4, p. 701-710, 2005
As plântulas crescidas até $7,5 \mathrm{~cm}$ de profundidade no Chernossolo tratado ou não com sulfentrazone apresentaram-se menores que as das demais profundidades quando o solo foi submetido à precipitação de até $60 \mathrm{~mm}$. Com 90 mm e aplicação do sulfentrazone, esse efeito se estendeu até $17,5 \mathrm{~cm}$. Dentro de cada profundidade, verificou-se efeito apenas nas plântulas oriundas da semeadura aos $2,5 \mathrm{~cm}$ no solo tratado com sulfentrazone e submetido aos três índices pluviométricos, que se mostraram menores que as respectivas testemunhas (Tabela 8).

As plântulas de sorgo nos $2,5 \mathrm{~cm}$ de profundidade em solo submetido a até $60 \mathrm{~mm}$ de precipitação obtiveram menores biomassas que as das demais profundidades, principalmente quando o solo foi tratado com sulfentrazone; com $90 \mathrm{~mm}$ de precipitação se estendeu até $22,5 \mathrm{~cm}$. Quando se analisou o efeito dos tratamentos dentro de cada profundidade, não se verificou diferença significativa em relação às respectivas testemunhas (Tabela 9).

Algumas propriedades dos solos, como $\mathrm{pH}$, teor de argila, ferro total, matéria orgânica e cristalinidade dos óxidos de ferro, podem reduzir a eficácia dos herbicidas, influenciando as perdas por lixiviação (Upchurch, 1966). Paula Neto (1999), estudando a influência de atributos de diferentes classes de solos (LVA, LV, LVdf e NV) na eficácia do sulfentrazone no controle da tiririca (Cyperus rotundus), observou que a eficácia diminuiu com o aumento no teor de óxidos de ferro e que os teores de argila e de matéria orgânica não afetaram a eficácia, sendo o LVdf e NV os solos mais limitantes ao uso desse herbicida.

Um dos fatores que influenciaram a ação do herbicida foi a saturação do solo, visto que, quanto maior o índice pluviométrico, maior foi a intensidade de injúria nas plântulas, principalmente quando se compararam os efeitos de $90 \mathrm{~mm}$ de precipitação com os de 30 e $60 \mathrm{~mm}$. Alves et al. (1999) verificaram que em um LV o sulfentrazone proporcionou excelente controle da tiririca independentemente da umidade, enquanto em um $\mathrm{NV}$ ele somente controlou quando a umidade do substrato era ou foi elevada para $90 \%$ (p/p). 
Tabela 6 - Emergência das plântulas de sorgo (\%), no Latossolo Vermelho (LV), obtida no desdobramento da interação entre as diferentes profundidades e os tratamentos com e sem aplicação do sulfentrazone sob as diferentes precipitações (média de três repetições)

\begin{tabular}{|c|c|c|c|c|c|c|}
\hline \multirow{2}{*}{$\begin{array}{c}\text { Profunfidade } \\
(\mathrm{cm})\end{array}$} & \multicolumn{3}{|c|}{ Sulfentrazone } & \multicolumn{3}{|c|}{ Testemunha } \\
\hline & $30 \mathrm{~mm}$ & $60 \mathrm{~mm}$ & $90 \mathrm{~mm}$ & $30 \mathrm{~mm}$ & $60 \mathrm{~mm}$ & $90 \mathrm{~mm}$ \\
\hline 2,5 & $57,65 \mathrm{Ab}^{1 /}$ & $75,57 \mathrm{ABab}$ & $84,18 \mathrm{Aa}$ & $59,89 \mathrm{Ab}$ & $72,77 \mathrm{Aab}$ & 72,54 Aab \\
\hline 7,5 & $64,71 \mathrm{Aa}$ & $81,39 \mathrm{ABa}$ & $69,75 \mathrm{Aa}$ & $64,71 \mathrm{Aa}$ & $64,16 \mathrm{Aa}$ & $75,57 \mathrm{Aa}$ \\
\hline 12,5 & $78,36 \mathrm{Aa}$ & $66,95 \mathrm{Ba}$ & $73,32 \mathrm{Aa}$ & $75,67 \mathrm{Aa}$ & $84,18 \mathrm{Aa}$ & $66,95 \mathrm{Aa}$ \\
\hline 17,5 & $64,71 \mathrm{Aa}$ & $64,71 \mathrm{Ba}$ & $79,14 \mathrm{Aa}$ & $67,50 \mathrm{Aa}$ & $75,57 \mathrm{Aa}$ & $64,16 \mathrm{Aa}$ \\
\hline 22,5 & $66,96 \mathrm{Aa}$ & $64,71 \mathrm{Ba}$ & $66,96 \mathrm{Aa}$ & $59,89 \mathrm{Aa}$ & $78,36 \mathrm{Aa}$ & 78,36 Aa \\
\hline 30,0 & $59,67 \mathrm{Ac}$ & $90,00 \mathrm{Aa}$ & $84,18 \mathrm{Aab}$ & $66,95 \mathrm{Abc}$ & $72,54 \mathrm{Aabc}$ & $72,54 \mathrm{Aabc}$ \\
\hline
\end{tabular}

1/ Médias seguidas de mesma letra não diferem significativamente pelo teste de Tukey a 5\%. Letras maiúsculas, na coluna, comparam os efeitos das diferentes profundidades. Letras minúsculas, na linha, comparam os efeitos das precipitações sem aplicação e com aplicação do sulfentrazone.

Tabela 7 - Efeito da aplicação do sulfentrazone no Chernossolo (M), sob diferentes precipitações, sobre a altura, emergência e biomassa das plântulas de sorgo nas diferentes profundidades (média de três repetições)

\begin{tabular}{|c|c|c|c|c|}
\hline \multicolumn{5}{|c|}{ Herbicida x Precipitação (HP) } \\
\hline \multirow{2}{*}{ Tratamento } & Precipitação & Altura & Emergência & Biomassa \\
\hline & $(\mathrm{mm})$ & $(\mathrm{cm})$ & $(\%)$ & (g) \\
\hline \multirow{3}{*}{ Aplicação de sulfentrazone } & 30 & $4,12 \mathrm{~A}^{1 / \prime}$ & $71,42 \mathrm{~A}$ & $0,0264 \mathrm{~A}$ \\
\hline & 60 & $3,54 \mathrm{~A}$ & $73,23 \mathrm{~A}$ & $0,0224 \mathrm{~A}$ \\
\hline & 90 & $3,33 \mathrm{~A}$ & $72,77 \mathrm{~A}$ & $0,0181 \mathrm{~A}$ \\
\hline \multirow{3}{*}{ Testemunha sem aplicação } & 30 & $4,54 \mathrm{~A}$ & $67,46 \mathrm{~A}$ & $0,0305 \mathrm{~A}$ \\
\hline & 60 & $4,06 \mathrm{~A}$ & $76,59 \mathrm{~A}$ & $0,0269 \mathrm{~A}$ \\
\hline & 90 & $3,89 \mathrm{~A}$ & $74,35 \mathrm{~A}$ & $0,0262 \mathrm{~A}$ \\
\hline & Profundidade $(\mathrm{cm})$ & \multicolumn{3}{|c|}{ Profundidade $(\mathrm{P})$} \\
\hline & 2,5 & $2,41 \mathrm{D}$ & $71,11 \mathrm{~A}$ & $0,0129 \mathrm{E}$ \\
\hline & 7,5 & $3,43 \mathrm{C}$ & $72,26 \mathrm{~A}$ & $0,0197 \mathrm{D}$ \\
\hline & 12,5 & $4,04 \mathrm{~B}$ & $74,91 \mathrm{~A}$ & $0,0246 \mathrm{CD}$ \\
\hline & 17,5 & $4,20 \mathrm{~B}$ & $75,73 \mathrm{~A}$ & $0,0279 \mathrm{BC}$ \\
\hline & 22,5 & $4,67 \mathrm{~A}$ & $71,58 \mathrm{~A}$ & $0,0308 \mathrm{AB}$ \\
\hline & 30,0 & $4,72 \mathrm{~A}$ & $70,24 \mathrm{~A}$ & $0,0346 \mathrm{~A}$ \\
\hline \multicolumn{2}{|l|}{$\mathrm{F}_{\mathrm{HP}}$} & $1,31 \mathrm{NS}$ & $1,19 \mathrm{NS}$ & $1,27 \mathrm{NS}$ \\
\hline \multicolumn{2}{|l|}{$\mathrm{F}_{\mathrm{P}}$} & $88,28 * *$ & $0,56 \mathrm{NS}$ & $39,30 * *$ \\
\hline \multicolumn{2}{|c|}{ HP x P } & $5,82 * *$ & $0,86 \mathrm{NS}$ & $2,29 * *$ \\
\hline \multicolumn{2}{|c|}{$\mathrm{CV}_{\mathrm{HP}}(\%)$} & 40,89 & 16,47 & 64,62 \\
\hline \multicolumn{2}{|c|}{$\mathrm{CV}_{\mathrm{P}}(\%)$} & 10,07 & 17,15 & 21,19 \\
\hline
\end{tabular}

1/ Médias seguidas de mesma letra não diferem significativamente pelo teste de Tukey a $5 \%$. ** e *: Significativo a 1 e $5 \%$ pelo teste $\mathrm{F}$, respectivamente; NS: não-significativo pelo teste F.

Com o aumento da saturação do solo, houve aumento na percolação do produto no perfil do solo somente no Chernossolo (M), no qual se observou atividade do herbicida ao longo do perfil, principalmente com $90 \mathrm{~mm}$ de precipitação. Entretanto, no Latossolo Vermelho (LV), houve adsorção do produto nas suas camadas superficiais, mas com pouco efeito sobre as plântulas; com a precipitação de $90 \mathrm{~mm}$, observou-se que ocorreu uma disponibilidade do produto. Rossi et al. (2003) relatam que o comportamento do sulfentrazone no perfil de um Nitossolo Vermelho (NV) e em um Neossolo Quartzarênico foi diferenciado: o segundo apresentou maior mobilidade do que o primeiro e, ainda, com aumento do teor de umidade do solo (90 mm) ocorreu maior disponibilidade do produto, mesmo em solos com baixa mobilidade. 
Tabela 8 - Altura das plântulas de sorgo (cm), no Chernossolo (M), obtida no desdobramento da interação entre as diferentes profundidades e os tratamentos sem aplicação e com aplicação do sulfentrazone e as diferentes precipitações (média de três repetições)

\begin{tabular}{|c|c|c|c|c|c|c|}
\hline \multirow{2}{*}{$\begin{array}{c}\text { Profundidade } \\
(\mathrm{cm})\end{array}$} & \multicolumn{3}{|c|}{ Sulfentrazone } & \multicolumn{3}{c|}{ Testemunha } \\
\cline { 2 - 7 } & $30 \mathrm{~mm}$ & $60 \mathrm{~mm}$ & $90 \mathrm{~mm}$ & $30 \mathrm{~mm}$ & $60 \mathrm{~mm}$ & $90 \mathrm{~mm}$ \\
\hline 2,5 & $1,60 \mathrm{Cbc}^{1 /}$ & $1,19 \mathrm{Cc}$ & $1,10 \mathrm{Ec}$ & $3,61 \mathrm{Ca}$ & $3,53 \mathrm{Bab}$ & $3,44 \mathrm{BCab}$ \\
\hline 7,5 & $4,08 \mathrm{Ba}$ & $3,46 \mathrm{Ba}$ & $2,37 \mathrm{Da}$ & $4,07 \mathrm{BCa}$ & $3,51 \mathrm{Ba}$ & $3,11 \mathrm{Ca}$ \\
\hline 12,5 & $4,54 \mathrm{ABa}$ & $3,80 \mathrm{ABa}$ & $3,21 \mathrm{CDa}$ & $4,76 \mathrm{ABa}$ & $4,00 \mathrm{ABa}$ & $3,93 \mathrm{ABCa}$ \\
\hline 17,5 & $4,64 \mathrm{ABa}$ & $4,03 \mathrm{ABa}$ & $3,83 \mathrm{BCa}$ & $4,67 \mathrm{ABa}$ & $4,06 \mathrm{ABa}$ & $3,99 \mathrm{ABCa}$ \\
\hline 22,5 & $5,09 \mathrm{Aa}$ & $4,60 \mathrm{Aa}$ & $4,42 \mathrm{ABa}$ & $5,15 \mathrm{Aa}$ & $4,44 \mathrm{ABa}$ & $4,32 \mathrm{ABa}$ \\
\hline 30,0 & $4,76 \mathrm{ABa}$ & $4,15 \mathrm{ABa}$ & $5,08 \mathrm{Aa}$ & $4,96 \mathrm{ABa}$ & $4,83 \mathrm{Aa}$ & $4,52 \mathrm{Aa}$ \\
\hline
\end{tabular}

${ }^{1 /}$ Médias seguidas de mesma letra não diferem significativamente pelo teste de Tukey a 5\%. Letras maiúsculas, na coluna, comparam os efeitos das diferentes profundidades. Letras minúsculas, na linha, comparam os efeitos das precipitações sem aplicação e com aplicação do sulfentrazone.

Tabela 9 - Biomassa das plântulas de sorgo (g), no Chernossolo (M), obtida no desdobramento da interação entre as diferentes profundidades e os tratamentos com e sem aplicação do sulfentrazone e as diferentes precipitações (média de três repetições)

\begin{tabular}{|c|c|c|c|c|c|c|}
\hline \multirow{2}{*}{$\begin{array}{c}\text { Profundidade } \\
(\mathrm{cm})\end{array}$} & \multicolumn{3}{|c|}{ Sulfentrazone } & \multicolumn{3}{c|}{ Testemunha } \\
\cline { 2 - 7 } & $30 \mathrm{~mm}$ & $60 \mathrm{~mm}$ & $90 \mathrm{~mm}$ & $30 \mathrm{~mm}$ & $60 \mathrm{~mm}$ & $90 \mathrm{~mm}$ \\
\hline 2,5 & $0,0087 \mathrm{Bab}^{\mathrm{1}}$ & $0,0043 \mathrm{Bab}$ & $0,0013 \mathrm{Db}$ & $0,0227 \mathrm{Ba}$ & $0,0217 \mathrm{Bab}$ & $0,0187 \mathrm{BCab}$ \\
\hline 7,5 & $0,0257 \mathrm{Aa}$ & $0,0213 \mathrm{Aa}$ & $0,0073 \mathrm{CDa}$ & $0,0250 \mathrm{ABa}$ & $0,0223 \mathrm{AB}$ & $0,0167 \mathrm{Ca}$ \\
\hline 12,5 & $0,0267 \mathrm{Aa}$ & $0,0233 \mathrm{Aa}$ & $0,0183 \mathrm{BCa}$ & $0,0323 \mathrm{ABa}$ & $0,0247 \mathrm{AB}$ & $0,0223 \mathrm{BCa}$ \\
\hline 17,5 & $0,0290 \mathrm{Aa}$ & $0,0290 \mathrm{Aa}$ & $0,0223 \mathrm{Ba}$ & $0,0323 \mathrm{ABa}$ & $0,0270 \mathrm{AB}$ & $0,0277 \mathrm{BCa}$ \\
\hline 22,5 & $0,0347 \mathrm{Aa}$ & $0,0307 \mathrm{Aa}$ & $0,0217 \mathrm{Ba}$ & $0,0363 \mathrm{Aa}$ & $0,0310 \mathrm{AB}$ & $0,0307 \mathrm{AB}$ \\
\hline 30,0 & $0,0337 \mathrm{Aa}$ & $0,0257 \mathrm{Aa}$ & $0,0373 \mathrm{Aa}$ & $0,0343 \mathrm{ABa}$ & $0,0350 \mathrm{Aa}$ & $0,0413 \mathrm{Aa}$ \\
\hline
\end{tabular}

1/ Médias seguidas de mesma letra não diferem significativamente pelo teste de Tukey a 5\%. Letras maiúsculas, na coluna, comparam os efeitos das diferentes profundidades. Letras minúsculas, na linha, comparam os efeitos das precipitações sem aplicação e com aplicação do sulfentrazone.

Oppong \& Sagar (1992), estudando o movimento do triasulfuron em um perfil de solo, através de bioensaio, observaram que o conteúdo de matéria orgânica no solo e a quantidade e freqüência de chuva têm relação inversa e que tais fatores influenciaram diretamente a lixiviação do produto. Poll \& DuToit (1995), estudando a lixiviação dos herbicidas imazamethabenz-methyl e chlorsulfuron + metsulfuron-methyl em casa de vegetação em oito diferentes tipos de solos, observaram que os herbicidas lixiviaram somente até a profundidade de $6 \mathrm{~cm}$ em um solo de baixo $\mathrm{pH}$ e mais de $24 \mathrm{~cm}$ em um solo com pH elevado.

No Chernossolo (M), com pH de 5, 1 e teor de óxido de ferro de 3,28\%, não houve adsorção significativa do herbicida, observando-se incremento na atividade deste com o aumento da precipitação. A ação nas camadas superficiais foi intensa, porém com percolação para maiores profundidades, onde os sintomas visuais não foram muito fortes, mas suficientes para afetar o desenvolvimento das plântulas de sorgo. No Latossolo Vermelho (LV), com pH de 5,9 e teor de óxido de ferro de $15,12 \%$, observou-se maior ação do herbicida na camada superficial do solo, provavelmente em decorrência dos elevados teores de óxido de ferro.

Os óxidos e hidróxidos de ferro e alumínio são importantes constituintes da fração argila dos solos tropicais. As características de superfície e de carga fazem com que essas argilas participem de todas as reações de superfície que ocorrem no solo (Kämpf \& Curi, 1991).

Alves et al. (2004) constataram que o sulfentrazone teve comportamento diferenciado entre as classes de solos e a eficácia diminuiu com o aumento do teor de óxido de ferro nos solos, na seguinte ordem: LVAd, LVd, 
NVe, LVef e LVdf; as variações nos teores de argila e da matéria orgânica dos solos não interferiram na eficácia do herbicida.

Spadotto et al. (2005) afirmaram que o efeito do $\mathrm{pH}$ na sorção do sulfentrazone mostrou-se muito interessante. Por causa de seu valor elevado de pKa $(6,6)$, o Kd do sulfentrazone alcança valores "máximos" em valores elevados de $\mathrm{pH}$ do solo, quando comparado com o 2,4-D e o flumetsulam. Portanto, o valor de Kd do sulfentrazone não aumenta com a diminuição do $\mathrm{pH}$ em profundidades abaixo de $60 \mathrm{~cm}$ nos três solos estudados, os quais apresentavam valores de $\mathrm{pH}$ abaixo de 4,8 nessas profundidades.

Paes et al. (1999), estudando a mobilidade do dimethenamid aplicado em solos de diferentes características, verificaram que, simulando uma precipitação de 45 e $90 \mathrm{~mm}$ de chuva sobre o solo arenoso, o produto foi fortemente arrastado. Já em textura areiafranca, com $45 \mathrm{~mm}$ de chuva o produto permaneceu nos 10 a $15 \mathrm{~cm}$ de profundidade, e com $90 \mathrm{~mm}$ de chuva, nos 20 a $30 \mathrm{~cm}$. Todavia, no argiloso e no franco-argilo-arenoso o comportamento foi igual, estabelecendo-se nos $5 \mathrm{~cm}$ superficiais.

Oliveira et al. (1999), aplicando flumioxazin e metribuzin em um solo Podzólico VermelhoAmarelo câmbico (PVC) e em Latossolo Vermelho-Amarelo textura média (LVm), com simulação de chuva de 45 e 90 mm, observaram que o flumioxazin no PVC não ultrapassou $5 \mathrm{~cm}$ superficiais; já o $\mathrm{LVm}$ atingiu $10 \mathrm{~cm}$ superficiais e o metribuzin $20 \mathrm{~cm}$ no PVC úmido e $45 \mathrm{~cm}$ no $\mathrm{LVm}$ seco.

Portanto, a mobilidade do sulfentrazone teve comportamento diferenciado entre as classes de solos, sendo mais móvel no $\mathrm{M}$ que no LV. Ainda, a atividade desse herbicida aumentou com o teor de umidade do solo; $90 \mathrm{~mm}$ de precipitação disponibilizaram o produto, mesmo no solo de baixa mobilidade desse herbicida.

\section{LITERATURA CITADA}

ALVES, P. L. C. A. et al. Efeitos do teor de umidade do solo sobre a eficiência do herbicida sulfentrazone no controle da tiririca (Cyperus rotundus L.). In: CONGRESO ALAM, 14.; CONGRESO ANUAL COMALFI, 29., 1999, Cartagena. Resumenes... Cartagena: 1999. p. 74.
ALVES, P. L. C. A.; MARQUES JÚNIOR, J.; FERRAUDO, A. S. Soil attributes and the efficiency of sulfentrazone on control of purple nutsedge (Cyperus rotundus L.). Sci. Agric., v. 61, n. 3, p. 319-325, 2004.

BRADY, N. C. The nature and properties of soils. 8.ed. New York: Macmillan, 1974. 639 p.

EMPRESA BRASILEIRA DE PESQUISA AGROPECUÁRIA - EMBRAPA. Serviço Nacional de Levantamento e Conservação de Solos. Manual de métodos de análise de solos. Rio de Janeiro: EMBRAPA, SNLCS, 1979. 247 p.

EMPRESA BRASILEIRA DE PESQUISA AGROPECUÁRIA - EMBRAPA. Serviço Nacional de Levantamento e Conservação de Solos. Sistema Brasileiro de Classificação de Solos. Rio de Janeiro: 1999. 412 p.

EUROPEAN WEED RESEARCH COUNCIL. Cittee of methods in weed research. Weed Res., v. 4, p. 88, 1964.

FONTES, M. P. F.; NEED, S. B. Iron oxides in selected brazilian oxisols: I. Mineralogy. Soil Sci. Soc. Am. J., v. 55, p. 1143-1149, 1991.

GREEN, R. E. Pesticide-clay-water interactions. In: GUELZI, W.D. (Ed.) Pesticides in soil and water. Madinson: SSSA, 1974. p. 3-37.

KÄMPF, N.; CURI, N. Argilominerais e óxidos em solos. In: LEPSCH, I. F. et al. (Eds.) Gênese, morfologia, classificação e levantamento de solos. Campinas: Sociedade Brasileira de Ciência do Solo, 1991. (no prelo)

KÄMPF, N.; SCHWERTMAN, U. Relações entre os óxidos de ferro e a cor em solos cauliníticos do Rio Grande do Sul. R. Bras. Ci. Solo, v. 7, p. 27-31, 1983.

LOUX, M. M.; LIBEBL, R. A.; SLIFE, F. W. Adsorption of imazaquin and imazethapyr on soils, sediments, and selected adsorbents. Weed Sci., v. 37, p. 712-718, 1989.

MANDHUN, Y. A.; YOUNG, J. L.; FREED, V. H. Binding of herbicides by water-soluble organic materials from soil. J. Environ. Quality, v. 15, p. 64-68, 1986.

NICHOLLS, P. H. Factors influencing entry of pesticides into soil water. Pest. Sci., v. 22, p. 123-137, 1988.

OLIVEIRA, J. B. Classes gerais de solos do Brasil: guia auxiliar para seu reconhecimento. Jaboticabal: FUNEP, 1992. $201 \mathrm{p}$.

OLIVEIRA, J. B.; PRADO, H. Levantamento pedológico semidetalhado do estado de São Paulo: quadrícula de Ribeirão Preto. Campinas: Instituto Agronômico de Campinas, 1987. 133 p. (Boletim Científico, 7).

Planta Daninha, Viçosa-MG, v. 23, n. 4, p. 701-710, 2005 
OLIVEIRA, M. F. et al. Lixiviação de flumioxazin e metribuzin em dois solos em condições de laboratório. Planta Daninha, v. 17, p. 207-215, 1999.

OPPONG, F. K.; SAGAR, G. R. The activity and mobility of triasulfuron in soil as influenced by organic matter, duration, amount and frequency of rain. Weed Res., v. 32, p. $157-165,1992$.

PAES, J. M. V. et al. Mobilidade do dimethenamid em diferentes solos. Planta Daninha, v. 17, p. 31-39, 1999.

PAULA NETO, J. F. Influência de atributos de solos na eficiência do sulfentrazone no controle de tiririca (Cyperus rotundus L.) 1999. 80 f. Monografia (Trabalho de graduação em Agronomia) - Universidade Estadual Paulista "Júlio de Mesquita Filho", Jaboticabal, 1999.

POLL, C. F.; DU-TOIT, D. Leaching depth of imazamethabenz methyl and chlorsulfuron + metsulfuron methyl in different soils. Appl. Plant Sci., v. 9, p. 43-47, 1995.

RAIJ, B. van; QUAGGIO, J. A. Métodos de análise de solo para fins de fertilidade. Campinas: Instituto Agronômico de Campinas, 1983. 31 p. (Boletim Técnico, $81)$.

RESENDE, M. et al. Pedologia: base para distinção de ambientes. Viçosa: NEPUT, 1995. 304 p.

RODRIGUES, B. N.; ALMEIDA, F. S. Guia de herbicidas 5.ed. Londrina: Edição dos autores, 2005. p. 484-490.
RODRIGUES, B. N. et al. Comportamento de herbicidas pré-emergentes aplicados sobre cobertura morta em plantio direto. In: CONGRESSO BRASILEIRO DA CIÊNCIA DAS PLANTAS DANINHAS, 22., 2000, Foz do Iguaçu.

Resumos... Foz do Iguaçu: 2000. p. 380.

ROSSI, C. V. S.; ALVES, P. L. C. A.; MARQUES JÚNIOR, J. Mobilidade do sulfentrazone em nitossolo vermelho e em neossolo quartzarênico. Planta Daninha, v. 21, n. 1, p. 207-215, 2003.

SENESI, N.; BRUNETTI, G.; LA CAVA, P. Adsorption of alachlor by humic acids from sewage and amended and non-amended soils. Soil Sci., v. 157, p. 176-184, 1994.

SPADOTTO, C. A.; HORNSBY, A. G.; GOMES, M. A. F. Sorption and leaching potential of acidic herbicides in brazilian soils. J. Environ. Sci. Health., v. B40, n. 1, p. 29-37, 2005.

SPRANKLE, P.; MEGGITT, W. F.; PENNER, D. Adsorption, mobility, and microbial degradation of glyphosate in the soil. Weed Sci., v. 23, p. 229-234, 1975.

UPCHURCH, R. P. Behavior of herbicides in soil. Res. Rev., v. 16, p. 45-85, 1966.

VELINI, E. D. Comportamento de herbicidas no solo. In: SIMPÓSIO NACIONAL SOBRE MANEJO DE PLANTAS DANINHAS EM HORTALIÇAS, 1992, Botucatu.

Resumos... Botucatu: 1992. p.44-64. 